\title{
The red eye of renal failure: a crystal induced inflammation?
}

\author{
N Klaassen-Broekema, O P van Bijsterveld
}

\begin{abstract}
Of 57 patients with chronic renal failure and calcification of the anterior membranes of the eye eight developed inflammatory reactions, clinically indistinguishable from pingueculitis. In three patients an acute inflammatory reaction of the episcleral tissue and the conjunctiva over it developed which we considered to represent the red eye of renal failure. In these patients massive shedding of calcium phosphate salts was clinically evident. Histopathologically in all these patients calcific deposits were observed. Although sporadically polymorphonuclear leucocytes were present in the inflamed tissues we could not demonstrate crystal phagocytosis. We believe that in the red eyes in renal failure and, more specifically, in the red eyes of renal failure a crystal induced inflammatory mechanism is not operative.

(Brf Ophthalmol 1992; 76: 578-581)
\end{abstract}

In patients with renal failure requiring regular haemodialysis, calcific deposits in the conjunctiva and cornea are common. As calcium phosphate salts are sparingly soluble and, as for the precipitation of the salt, the product of the concentration of the positively and negatively charged part of the salt is constant, an increase in either serum calcium or serum phosphorus concentration, large enough to exceed the in vivo solubility product, will lead to the deposition of calcium phosphate salts in the form of microcrystalline hydroxyapatite. ${ }^{1}$

An acute inflammatory response in the joints associated with the presence and phagocytosis of urate crystals has been described. ${ }^{2}$ Hydroxyapatite crystals also have a marked phlogistic potential. ${ }^{3}$ After being ingested by polymorphonuclear leucocytes they lead to cell death and to the release of large quantities of enzymes all capable of initiating inflammatory reactions. The crystals extruded in the extracellular tissue set in motion a new cycle of phagocytosis, cell death, and the release of inflammatory mediators continuing the inflammatory response. ${ }^{4}$

Berlyne $^{5}$ formulated the skilful theory of crystal induced inflammation, a dose related and reversible inflammatory reaction, ${ }^{6}$ for the explanation of the mechanism of the red eyes of renal failure. The histopathological study of Berlyne demonstrated the presence of subconjunctival polymorphonuclear leucocytes and calcium phosphate crystals small enough to be phagocytosed, a prerequisite for the crystal induced inflammation theory. However, no mention was made of phagocytosis and he did not pursue the crystal induced inflammation concept to explain the red eyes in renal failure.

Berlyne and Shaw ${ }^{7}$ took a conjunctival biopsy of a patient they considered to present with the red eye in renal failure. However their biopsy may have been taken from an inflamed pinguecula as demonstrated by the figure shown in their report. We therefore studied biopsies from patients with a distinctly different type of inflammatory reaction, clinically characterised by a waxy-red hyperaemia of the episclera and the conjunctiva over it, patients who were biochemically characterised by a high calcium/ phosphorus ratio. ${ }^{8}$ In addition we examined biopsies that were taken from patients without any inflammatory reactions of the outer membranes of the eye and also from patients with inflammatory reactions clinically indistinguishable from pingueculitis.

\section{Patients and methods}

The patient groups were identified both clinically and biochemically: group A consisted of 46 patients with calcium deposits but without the occurrence of an inflammatory reaction during the observation period, which was 6 years on average. Group B consisted of eight patients with calcification and inflammatory reactions associated with pingueculae. We considered these patients to represent the red eyes in renal failure. Group C consisted of three patients with an inflammatory reaction resembling diffuse episcleritis, extending well beyond the palpebral aperture, and an associated conjunctivitis which we considered the red eye of renal failure. Biochemically these patient groups were characterised on the basis of the relationship between the serum calcium and phosphorus concentration. Fifty healthy persons, matched in sex and comparable in age and weight, were used as controls.

Conjunctival biopsies were taken from patients of the three main groups and were examined by light microscopy. The tissues were fixed in phosphate buffered neutral formalin (10\%). The histological sections were processed according to standard methods. The histochemical stains used were haematoxylin and eosin, to reveal the general cell structure, Giemsa stain and toluidine blue for the study of 
Table 1 The average calcium/phosphorus product and the number of persons in groups $A, B, C$, and the control group $(C o)$ are shown with the standard deviations

\begin{tabular}{lcllc}
\hline & Group & & & \\
\cline { 2 - 5 } & $A$ & $B$ & $C$ & $C o$ \\
\hline Average & 4.59 & 5.02 & 6.62 & 3.13 \\
Number & 46 & 8 & 3 & 50 \\
SD $(\mathrm{n}-1)$ & 1.29 & 1.41 & 1.62 & 0.46 \\
\hline
\end{tabular}

Table 2 The average serum calcium/phosphorus ratio, the number of patients and the standard deviation in patients of groups $A, B, C$, and the control group $(C o)$

\begin{tabular}{lcllc}
\hline & Group & & & \\
\cline { 2 - 5 } & $A$ & $B$ & $C$ & Co \\
\hline Average & 1.51 & 1.44 & 2.00 & 1.90 \\
Number & 46 & 8 & 3 & 50 \\
SD (n-1) & 0.56 & 0.39 & 0.75 & 0.24 \\
\hline
\end{tabular}

polymorphonuclear leucocytes. The van Gieson stain was used to study degeneration of connective tissue. Calcium deposits were shown by the von Kóssa stain. Fresh tissue biopsies were taken and examined with immunofluorescence techniques to reveal tissue complement activation.

\section{Results}

\section{Serum calcium and phosphorus product}

In Table 1 the average values of the serum calcium-phosphorus product of patient groups $\mathrm{A}, \mathrm{B}, \mathrm{C}$, and the control group are shown. Statistically there was a significant difference between the patient groups and the control group. The patient groups all showed higher values than the control group. This is shown graphically in Figure 1. From this figure it is apparent that between the patient groups there was also a difference; statistically this difference was significant.

The highest calcium phosphorus product was observed in patients of group C. These patients had inflammatory reactions characterised by a diffuse waxy red episcleral and conjunctival hyperaemia. However in this group the average value of the serum calcium-phosphorus product exceeded the empirically observed serum

Figure 1 The average serum calcium (mmolll) and phosphorus (mmolll) confidence interval, of 46 patients

patients
$(A)$ with calcific deposits but without inflammatory reactions, of eight patients

(B) associated with pingueculae, and of three patients $(C)$ characterised by a waxy red diffuse episcleral inflammatory reaction and the conjunctiva over it, extending well beyond the palpebral fissure, at the height of the inflammatory reaction. The calcium phosphorus product of the control group $(\mathrm{Co})$ is also shown. The broken line shows the empirical calcium phosphorus product above which the red eyes in renal failure were said to be associated. calcium-phosphorus product value that, in the

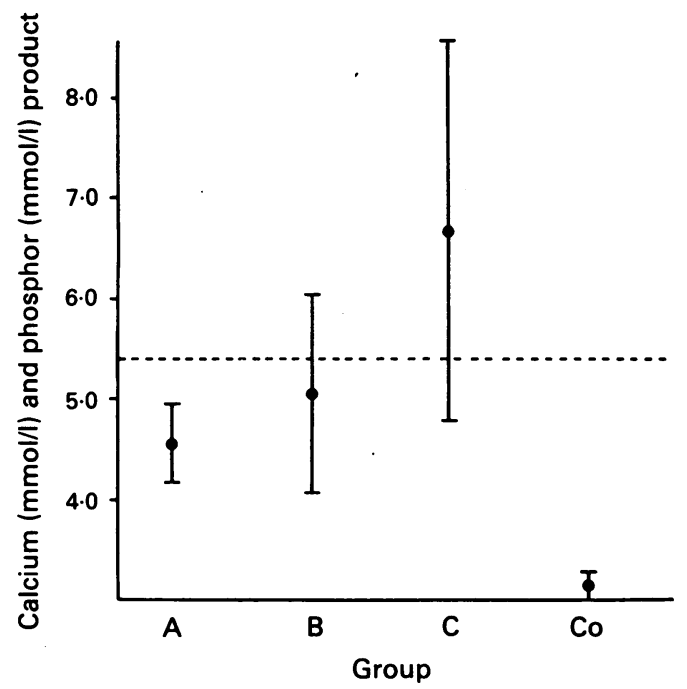

Table 3 Percentage increase of the serum calcium and serum phosphorus concentration in patients of groups $A, B$, and $C$ in comparison with these values of the control group

\begin{tabular}{lrrl}
\hline & Group & & \\
\cline { 2 - 4 } & \multicolumn{1}{c}{$A$} & $B$ & $C$ \\
\hline Calcium & $3 \cdot 2$ & $7 \cdot 7$ & $31 \cdot 7$ \\
Phosphorus & 30.0 & 32.6 & 32.6 \\
\hline
\end{tabular}

past, was associated with the red eye of renal failure.

\section{Serum calcium/phosphorus ratio}

In Table 2 the average serum calcium/ phosphorus ratios are shown for the patient groups A, B, C, and the control group. The control group and group $\mathrm{C}$ had the highest value. There was a statistically significant difference in the serum calcium/phosphorus ratio between the patient groups and the control group but not among the patient groups. The inability to demonstrate a difference between group $A$ and $B$ on the one hand and group $C$ on the other was the consequence of the smaller number of patients in group C. The difference between the patient groups we observed, however, was found to be dependent on the contribution of the average serum calcium concentration to the ratio; the serum phosphorus concentration was constant, as shown in Table 3.

\section{Histopathology}

A conjunctival biopsy of a representative patient from group A showed marked subepithelial calcium deposits. There was a certain amount of elastotic degenerated connective tissue. No inflammatory cells in or around the calcific deposits were observed, but perivascularly some polymorphonuclear leucocytes were seen. There was no distension of the conjunctival or episcleral vessels.

In the biopsies of patients from group B marked deposits of subepithelial calcium were also seen. The collagen fibres were degenerated. A localised, moderate increase in polymorphonuclear leucocyte infiltration was seen in almost half of the cases. Sporadic leucocytes were observed in $14 \%$ of the biopsies; however these inflammatory cells may be completely absent. No crystal phagocytosis of calcific material was observed. The histopathology of this group is compatible with that of pingueculitis.

In the biopsies of patients of group $\mathrm{C}$ both conjunctival and episcleral vessels were markedly dilated. There was a marked degree of elastotic degeneration of collagen fibres. Calcium salts were present subepithelially. A few degranulating mast cells near the calcium deposits were observed. A moderate inflammatory reaction was shown in all patients, characterised by pavementing of the endothelium of the vascular walls by polymorphonuclear leucocytes; these cells were also visible perivascularly. A few eosinophilic cells, lymphocytes, and plasma cells were among the inflammatory cells. The inflammatory reaction was diffuse and nongranulomatous (Fig 2). Polymorphonuclear cells 


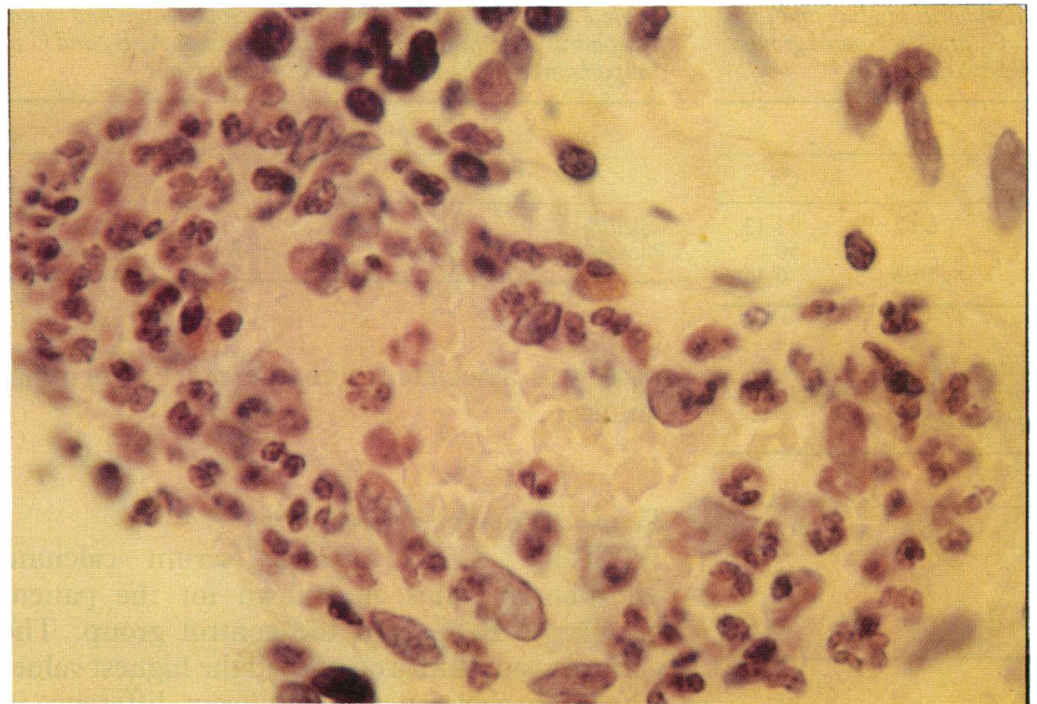

Figure 2 Histopathology of a conjunctival biopsy of a patient from group $C$, clinically characterised by a waxy red episcleral hyperaemia extending beyond the palpebral aperture. Pavementing of the endothelium by polymorphonuclear leucocytes of the vascular wall is shown. Also visible are lymphocytes, eosinophilic cells, plasma cells, as well as perivascular infiltration of leucocytes. Haematoxylin and eosin, $\times 900$.

were not located in the areas of calcification (Fig 3). No crystal phagocytosis was observed. The histopathology of this group is compatible with primary, simple episcleritis. No complement activation was detected by immunofluorescence.

\section{Discussion}

After being phagocytosed microcrystalline hydroxyapatite is very toxic to leucocytes ${ }^{9}$ because these crystals are membranolytic. It is therefore not surprising that for Berlyne the development of the red eye in renal failure is none other than the mechanism of crystal induced arthritis. He looked at the conjunctival sac as a specialised joint in which the moving surfaces are the lids and eyeball; the conjunctiva being analogous to the synovial membrane. The presence of polymorphonuclear cells, mono-

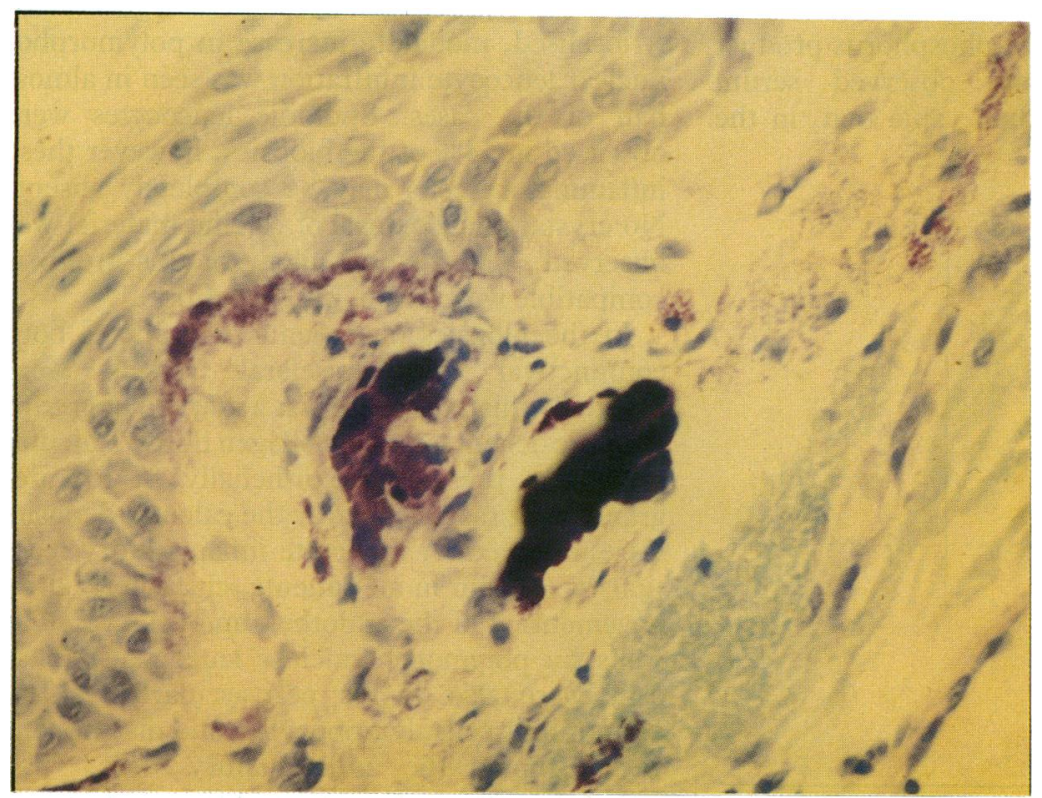

Figure 3 Patient from group C: subepithelial calcific deposits as a large plaque adjacent to small calcific granules without any crystal phagocytosis. Giemsa stained, ×410. nuclear cells, as well as crystals small enough to be phagocytosed, being the conditions for the induction of a crystal induced inflammation, seems to favour such a mechanism.

Hydroxyapatite crystal deposition in soft tissues will occur when the serum concentrations of calcium and phosphate exceed the solubility product - that is, in a marked supersaturated solution. In vitro the serum calcium/phosphorus ratio determines the type of salt formed. In a high calcium/phosphorus ratio of 1.67 or more, salts are deposited in a crystalline form, while a low ratio results in amorphous deposits.

If the concentration of calcium and phosphorus ions increase homogeneically, large crystals are formed; small crystals are deposited if the ion concentrations increase inhomogeneically. In a situation that favours the precipitation of calcium salts of a crystalline nature, and in view of the pathophysiology of renal failure one can expect the deposition of predominantly microcrystalline deposits of hydroxyapatite, which was demonstrated. ${ }^{\mathrm{s}}$

Particularly in the rather acute and pronounced diffuse episcleral and conjunctival inflammatory reactions of the patients of group $C$, the average serum calcium/phosphorus ratio was $2 \cdot 00$, the result of the rather marked increase of the serum calcium concentration. Here, one can expect massive shedding of crystals, which we observed clinically, one of the prerequisites of crystal induced inflammation.

Hydroxyapatite crystals, most of which are less than $0.5 \mu \mathrm{m}$ long, cannot be seen by light microscopy and crystal phagocytosis could be difficult to demonstrate in a routine histopathological examination. Hydroxyapatite crystals have, however, a marked tendency to clump and to arrange themselves within a connective tissue matrix. ${ }^{1011}$ These clumps of crystal and matrix can be seen by light microscopy, free or intraleucocytic, as in periarthritis.

In spite of the presence of subconjunctival extracellular hydroxyapatite crystals in an acutely inflamed episcleral and conjunctival tissue, we were not able to observe crystal phagocytosis. In group $\mathrm{C}$ and also in the majority of the patients in group $B$ there is an increased polymorphonuclear leucocyte infiltration, but they are not in the vicinity of calcific deposits. We did not observe chemotaxis exerted by hydroxyapatite crystals in the conjunctiva.

The absence of crystal induced phagocytosis in the presence of hydroxyapatite crystals suggests a 'switch-off' phenomenon. Phagocytosis of crystals is expedited when certain proteins are adsorbed to the surface of the crystal $^{12}$ and inhibited if crystals are coated by competing proteins. One can hypothesise that the absence of phlogistic activity of the hydroxyapatite crystals in the red eye of renal failure might be related to adsorbed molecules such as hyaluronate ${ }^{13}$ or glycoproteins..$^{14}$ Adaptation to crystals manifested clinically by their silent presence might be explained by such a mechanism. 
1 Berkow JW, Fine BS, Zimmerman LE. Unusual ocular calcification in hyperparathyroidism. Am $\mathcal{F}$ Ophthalmol 1968; 66: 812-24.

2 Faires JS, McCarty DJ. Acute arthritis in man and dog after intrasynovial injection of sodium urate crystals. Lancet 1962; ii: $682-4$.

3 McCarty DJ, Gatter RA. Recurrent acute inflammation associated with focal apatite crystal deposition. Arthritis Rheum 1966; 9: 804-19.

4 Maurer KH, Schumacher HR. Hydroxyapatite phagocytosis by human polymorphonuclear leucocytes. Ann Rheum Dis 1979; 38: 84-8.

5 Berlyne GM. Microcrystalline conjunctival calcification in renal failure, a useful clinical sign Lancet 1968; ii: 366-70. McCarty DJ, Gatter RA Brill JM, Hogan JM. Crystal deposition diseases. FAMA 1965; 193: 129-32.

7 Berlyne GM, Shaw AB. Red eyes in renal failure. Lancet 1967; i: $4-5$.

8 Klaassen-Broekema N, Bijsterveld OP van. Red eyes in renal failure. Br f Ophthalmol 1992; 76: 268-71.

9 Dieppe P, Hornby J, Swan A. Different effects of crystals on release of inflammatory mediators from human peripheral blood phagocytic cells. Ann Rheum Dis 1983; 42 (Suppl.): 112

10 Sokoloff L. The pathology of gout. Metabolism 1957; 6: 230

11 Bjelle AO. Morphological study of articular cartilage in pyrophosphate arthropathy. (Chondrocalcinosis articularis or calcium pyrophosphate dihydrate crystal deposition diseases. Ann Rheum Dis 1972; 31: 449-56.

12 Ginsberg MH, Kozin F, Chow D, May J, Skosey JL Adsorption of polymorphonuclear leucocyte lysosomal moficts 1977; 20 : 1538-42.

13 Brandt KD. The effect of synovial hyaluronate on the ingestion of monosodium urate crystals by leucocytes. Clin Chim Acta 1974; 55: 307-15.

14 Terkeltaub RA, Santoro DA, Mandel G, Mandel N. Serum and plasma inhibit neutrophil stimulation by hydroxyapatite crystals. Evidence that serum alpha-2-HS glycoprotein is a potent and specific crystal-bound inhibitor. Arthritis Rheum potent and specific
1988; 31: 1081-9. 